\title{
EL CONTROL DE LA AGRICULTURA DE EXPORTACIÓN LEVANTINA DURANTE LA GUERRA CIVIL (1936-1939)
}

\author{
JOSÉ MIGUEL SANTACREU SOLER \\ Universidad de Alicante
}

La mayoría de los autores que han estudiado o reflexionado en torno a la guerra civil española, tales como Josep María Bricall (1), María Carmen García-Nieto y Tuñón de Lara (2), Joseph Harrison (3), Juan Antonio Lacomba (4), Edward Malefakis (5) o Pierre Vilar (6,) coinciden en que, tras la división de España en dos zonas, el área republicana controló la mayor parte de la producción agrícola capaz de generar divisas. Se trataba de los cítricos, las vides, los almendros y los productos hortícolas; cultivos concentrados esencialmente en el Levante (7) español.

Según los datos de la Dirección General de Aduanas (8) reflejados en el cuadro 1, sólo las exportaciones de naranjas, cebollas y limones, producidos mayoritariamente en el Levante español, supusieron más del $40 \%$ del valor total de las exportaciones de alimentos de la Segunda República Española durante 1937 y cerca del $80 \%$ en la primera mitad de 1938. Si tenemos en cuenta que las sustancias alimenticias, en conjunto, significaron el $70 \%$ del valor total de las exportaciones de mercancías de la Segunda República en 1937 y más del $78 \%$ durante la primera mitad de 1938, podemos hacernos una idea aproximada de la importancia que tuvo durante la guerra la agri-

(1) BRICALL, J. M.: «La economía española (1936-1939)», p. 365, en La guerra civil española 50 años después, Labor, Barcelona, 1985, pp. 359-418.

(2) GARCIA-NIETO, M. a C., y TUÑÓN DE LARA, M.: «La guarra civil», p. 259, en Historia de España, dirigida por M. Tuñón de Lara, t. IX, Labor, Barcelona, 2. ${ }^{a}$ reim. 1983, pp. 243-48.

(3) HARRISON, J.: Historia económica de la España contemporánea, Vicens Vives, BarceIona, 1983, p. 203.

(4) LACOMBA, J. A.: Introducción a la Historia Económica de la España Contemporánea, Guadiana de Publicaciones, Madrid, 2. ${ }^{a}$ ed. 1972, p. 527.

(5) MALEFAKIS, E.: «La economía española y la guerra civil», en La economía española en el siglo XX. Una perspectiva histórica, Ariel, Barcelona, 1987, pp. 150-163.

(6) VILAR, P.: La guerra civil española, Grijalbo, Barcelona, 1986, p. 130.

(7) Según las estadísticas oficiales de la época, el Levante español lo constituian las provincias de Alicante, Castellón, Murcia y Valencia.

(8) DIRECCIÓN GENERAL DE ADUANAS: Resúmenes provisionales de estadística del Comercio Exterior de España (años 1937 y 1938), Madrid, 1938. 
cultura de exportación levantina para la obtención de divisas, clearings y compensaciones. En este sentido, Juan Velarde (9) sostiene que la huerta valenciana-murciana se convirtió, con la evolución de la guerra, en uno de los únicos activos que conservaba la Segunda República Española en 1938 capaz de generar cierta actividad económica.

\section{CUADRO 1}

\section{Valores en pesetas oro de las exportaciones de mercancías de la II República Española desde enero de 1937 hasta julio de 1938}

\begin{tabular}{|c|c|c|}
\hline \multirow{2}{*}{ MERCANCIÁS } & \multirow{2}{*}{ ENE./DIC. 1937} & \multirow{2}{*}{ ENE./JUN. 1938} \\
\hline & & \\
\hline 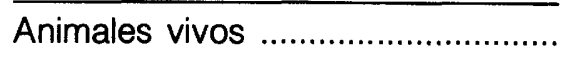 & $\overline{104}$ & - \\
\hline 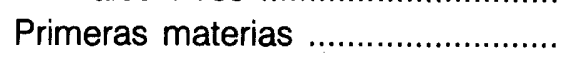 & 26.893.322 & 4.062 .880 \\
\hline 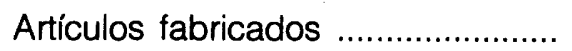 & 29.387 .388 & 8.286 .174 \\
\hline Sustancias alimenticias ...................... & 135.009 .623 & 44.320 .437 \\
\hline Totales & 191.290 .437 & 56.669 .491 \\
\hline \multicolumn{3}{|c|}{ Detalle de algunas sustancias alimenticias: } \\
\hline 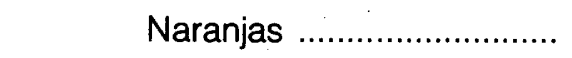 & 87.161 .290 & 30.992 .519 \\
\hline Limones ............................ & 5.332 .294 & 3.413 .430 \\
\hline  & 3.363 .358 & 724.077 \\
\hline Total ......................... & 95.856 .942 & 35.130 .026 \\
\hline
\end{tabular}

FUENTE: Resúmenes provisionales de estadística del comercio exterior de España.

No es extraño, pues, que en el seno de la zona republicana se desatase una lucha interna para controlar la agricultura de exportación levantina. Comerciantes particulares, organizaciones sindicales y órganos de gobierno local, provincial o autonómico se disputaron su control desde julio de 1936 hasta que, durante la segunda mitad de 1937, el Gobierno Negrín optó por asumir el pleno control de estas exportaciones. Hasta mayo de 1937 la Dirección General de Comercio reguló las exportaciones y éstas las efectuaron los comerciantes particulares, sindicatos y órganos de gobierno no estatales. Asi se de-

(9) VELARDE, J.: «La economía política de la guerra civil», p. 96, en La guerra civil española. Una reflexión moral 50 años después, Planeta, Barcelona, 1986, pp. 83-100. 
finió una etapa de la guerra caracterizada, en materia de exportaciones de productos agrícolas, por un control descentralizado de su comercialización y una férrea regulación estatal de las mismas. A partir de junio de 1937 el Gobierno Negrín empezó a controlar directamente la comercialización de la agricultura levantina de exportación, creando organismos adecuados para ello: las Centrales de Exportación. Así nació una segunda etapa de la guerra en materia de exportaciones de productos agrícolas caracterizada por un control estatal centralizado de la comercialización de la agricultura de exportación levantina. Durante esta segunda etapa, que se prolongó hasta el final de la guerra, se produjo el acceso del Gobierno de Franco, tras tomar Castellón entre abril y junio de 1938, a parte del territorio en el que se cultivaba este tipo de agricultura. El Gobierno ocupante también optó por un control centralizado de la comercialización de dicha agricultura, aunque con distintos planteamientos.

\section{LA AGRICULTURA DE EXPORTACIÓN LEVANTINA}

Para conocer las características y los problemas de la agricultura levantina durante la Segunda República contamos con un buen repertorio bibliográfico. En concreto, la agricultura del País Valenciano ha sido estudiada por Jordi Palafox (10) o J. A. Martínez, V. Soler y E. Reig (11), y la de Murcia, por J. A. Ayala (12). A nosotros no nos interesa establecer aquí las características ni los problemas de la agricultura levantina, sino discernir qué productos agrícolas cultivados en el Levante español eran los más importantes para la exportación y cuál era la información disponible en la época para discernirlos. Sobre todo la información con la que contaba el Gobierno.

Éste tuvo, en teroría, a su disposición el Anuario Estadístico de las Producciones Agrícolas de 1935 (13), elaborado por la Sección de Estadística y Economía Agrícola del Ministerio de Agricultura y el «lnforme de la Industria Pimentonera» que José María Sarabia remitió al comandante Eladio Fernández, del Batallón de Abastecimiento Mecanizado de Valencia, én agosto de 1937 (14).

(10) PALAFOX, J.: «Agricultura d'especulació i crisis económica. El Pais Valencià durant els anys trenta (1930-1936)», en Estudis d'História Agrária N. ${ }^{\circ} 3$, Barcelona, 1979, pp. 139-162.

(11) MARTÍNEZ, J. A.; SOLER, V., y REIG, E.: Historia de la economía valenciana, C. de Ah. de Valencia, Valencia, 1978.

(12) AYALA, J. A.: Murcia y su huerta en la /l República 1931-1939, Murcia, 1978.

(13) MINISTERIO DE AGRICULTURA (Subsecretaría. Secc. 4. a . Estadistica y Economía Agrícola): Anuario Estadístico de las Producciones Agrícolas. Año 1935 y 1936 para los agrios y el olivo. Madrid, 1936.

(14) Archivo Histórico Nacional-Sección Guerra Civil (AHN-GC). Salamanca: Serie Alicante-PS, leg. 15, exp. 11. 
Según esta información (cuadro 2), los cinco productos agrícolas de los que más quintales métricos se exportaron en 1935 fueron las naranjas, los vinos, las cebollas, las patatas y el aceite de oliva; sin embargo, los cinco productos agrícolas que mayor valor monetario alcanzaron con sus exportaciones fueron las naranjas, el aceite de oliva, los vinos, el pimentón y las almendras. De otro lado, los cinco productos agrícolas que exportaron la mayoría de su producción fueron las naranjas, las pasas, el pimentón, los limones y las uvas frescas.

Así, los productos que más relevancia tuvieron en las exportaciones españolas de 1935, según los datos a disposición del Gobierno republicano de la guerra, fueron las naranjas, vinos, cebollas, patatas, aceite de oliva, pimentón, almendras, pasas, limones y uvas frescas. Pero qué productos de éstos podia llamar la atención del Gobierno por cultivarse mayoritariamente en territorio leal de retaguardia y por ocupar un lugar destacado en las exportaciones? Desconocemos las circunstancias que indujeron al Gobierno Negrín a decantarse por la centralización de las exportaciones de determinados productos; aunque hemos elaborado un índice discriminante teórico que podría orientarnos sobre la decisión del Gobierno y, en último término, razonárnosla.

El índice está reflejado en el cuadro 3, compuesto por una tabla de contingencias de los cinco productos agrícolas españoles más exportados en 1935, según su volumen, valor y porcentaje del cultivo dedicado a la exportación, expresando el número de orden que ocupa en cada variable y por un ratio exportador medio de orden (REMO), para aclarar el orden de los casos conflictivos (15).

En el cuadro 3, las naranjas obtienen valores en todas las variables, los vinos, el aceite de oliva y el pimentón en dos y el resto de los productos no figuran más que en una variable. Analizando los productos agrícolas que puntúan en más de una variable se observa que de éstos en el Levante español se producía el $88,25 \%$ de las naranjas del país y el $82,03 \%$ del pimentón. Los dos productos eran una importante fuente de divisas debido a la magnitud de sus exportaciones y al valor que éstas alcanzaban: más de 146 millones de pesetas oro las naranjas y 26,4 millones el pimentón. A las naranjas habría que añadir los limones, ya que forman parte de la familia de los cítricos y no se pueden disociar de las naranjas a efectos agrícolas, comerciales y administrativos; además el Levante español producía el 64,02 \% de los limones españoles y sus exportaciones en 1935 se valoraron en 9 millones de

(15) EI REMO es el cociente de la suma del número de orden ocupado por la mercancía agricola en cada una de las variables dividida por el número de variables sumadas. 
pesetas oro. De los vinos y el aceite de oliva españoles el Levante sólo producia un $12 \%$ y un $6,4 \%$, respectivamente.

Según nuestro indice discriminante, las naranjas, el pimentón y los limones eran los principales productos de exportación que se cultivaban en Levante. Consecuentemente, el Gobierno Negrín tenía que decidirse por estos tres productos agrícolas de exportación a la hora de controlar la comercialización de las principales exportaciones agrícolas de la retaguardia leal a la República.

\section{CUADRO 2}

\section{Principales exportaciones agrícolas españolas de 1935 con su producción en el Levante español}

\begin{tabular}{|c|c|c|c|c|c|}
\hline \multirow[b]{2}{*}{ CONCEPTOS } & \multicolumn{3}{|c|}{ EXPORTACIÓN } & \multicolumn{2}{|c|}{ PRODUCCIÓN DE LEVANTE } \\
\hline & $\begin{array}{l}\text { Q. M. } \\
\text { EXPORTADOS }\end{array}$ & $\begin{array}{l}\text { MILLONES } \\
\text { DE PTAS. }\end{array}$ & $\begin{array}{c}\text { \% DE LA } \\
\text { PRODUCCIÓN }\end{array}$ & $\begin{array}{c}\text { Q. M. } \\
\text { PRODUCIDOS }\end{array}$ & $\begin{array}{l}\text { \% DE LA } \\
\text { PRODUCCIÓN } \\
\text { ESPAÑOLA }\end{array}$ \\
\hline 1. Naranjas ............ & 7.003 .432 & 146,44 & 76,9 & 8.037 .545 & 88,2 \\
\hline 2. Vinos (Hec.) .... & 1.317 .269 & 66,33 & 7,7 & $2.141 .715^{\mathrm{A}}$ & 12,5 \\
\hline 3. Cebollas ........... & 1.074 .265 & 12,14 & 17,9 & 3.287 .405 & 58,8 \\
\hline 4. Patatas .................. & 864.907 & 15,19 & 1,7 & 1.520 .208 & 3,5 \\
\hline \multicolumn{6}{|l|}{ 5. Aceite de } \\
\hline oliva ....................... & 620.653 & 82,53 & 14,1 & 280.228 & 6,4 \\
\hline 6. Uvas frescas ... & 408.759 & 11,72 & 26,1 & 739.593 & 34,7 \\
\hline 7. Arroz ……........... & 269.482 & 9,10 & 13,9 & 2.115 .929 & 72,5 \\
\hline 8. Almendras ${ }^{B} \ldots$ & 259.379 & 20,61 & 17,6 & 656.020 & 44,7 \\
\hline 9. Limones ............ & 200.697 & 9,00 & 39,3 & 326.873 & 64,0 \\
\hline 10. Melones ${ }^{C} \ldots \ldots$. & 122.123 & 1,44 & 1,8 & 1.211 .190 & 18,3 \\
\hline 11. Pasa .................. & 114.973 & 10,71 & 64,6 & 88.138 & 49,5 \\
\hline 13. Pimentón ......... & 109.000 & 26,40 & 60,4 & 148.000 & 82,0 \\
\hline
\end{tabular}

A Total de mostos.

B Almendras en pepita.

C Se ha empleado el coeficiente 2,214 para pasar de cientos a Q. M.

FUENTE: Anuario estadístico de las producciones agrícolas. 
CUADRO 3

Tabla de contingencias de los cinco productos agrícolas españoles más exportados en 1935 según su volumen, valor y finalidad exportadora del cultivo (se expresa el número de orden ) y valores REMO

(ratio exportador medio de orden)

\begin{tabular}{|c|c|c|c|c|}
\hline CONCEPTOS & VOLUMEN & VALOR & FINALIDAD EX. & REMO \\
\hline Naranjas ................... & $1 .^{\circ}$ & 1.0 & $1 .^{\circ}$ & 1,00 \\
\hline 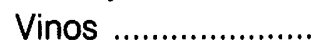 & $2 .^{\circ}$ & $3 .^{\circ}$ & & 5,00 \\
\hline Cebollas ..................... & $3 .^{\circ}$ & & & 5,30 \\
\hline 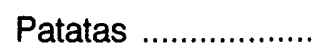 & $4^{\circ}$ & & & 7,30 \\
\hline Aceite de oliva ...... & $5 .^{\circ}$ & $2 .^{\circ}$ & & 5,00 \\
\hline Pimentón ................. & & $4 .^{\circ}$ & $3 .^{\circ}$ & 6,60 \\
\hline Almendras ............. & & $5 .^{\circ}$ & & 6,60 \\
\hline Pasas ........................ & & & $2 .^{\circ}$ & 7,50 \\
\hline Limones .................. & & & $4 .^{\circ}$ & 8,00 \\
\hline Uvas frescas .......... & & & $5 .^{\circ}$ & 6,30 \\
\hline
\end{tabular}

Como venimos trabajando estadísticamente con los cinco primeros productos de exportación, sería antimetódico limitarnos a analizar nada más que la comercialización de naranjas, pimentón y limones durante la guerra. Por ello, es conveniente escoger dos productos más de entre los que figuran en el cuadro 3 con una sola variable, siguiendo el mismo método empleado hasta ahora, para añadirlos en nuestro análisis. Los escogidos son las cebollas y la uva de mesa. Ello es así porque estos productos lograron en 1935 un REMO situado entre los cinco primeros de la nación, concretamente el cuarto y quinto lugar con un REMO de 5,30 y 6,30 , respectivamente, por detrás de las naranjas, vino y aceite de oliva, y porque en el Levante español se producían buena parte de los mismos: el $58,81 \%$ las cebollas y el $34,74 \%$ las uvas frescas.

Recapitulando. Naranjas, pimentón, limones, cebollas y uvas frescas centrarán nuestra atención a partir de ahora, al igual que acapararon el interés del Gobierno Negrín entre junio y septiembre de 1937, cuando procedió a controlar su comercialización mediante las Centrales de Exportación.

2. ETAPA DE CONTROL DESCENTRALIZADO (JULIO 1936-MAYO 1937)

El estallido de la guerra civil provocó una etapa de absoluta anormalidad 
que afectaría profundamente a la organización, funcionamiento, dirección y resultados del comercio exterior español. La contienda rompió el esquema de relaciones económicas internacionales y nacionales, subordinando los mecanismos comerciales a las exigencias de la economía de guerra (16).

En un primer momento, las exportaciones agricolas de la región levantina se paralizaron a causa de los problemas provocados, de un lado, por la requisa de los navíos de carga españoles efectuadas por el Estado con el fin de usarlos en las operaciones militares y por la resistencia de los buques extranjeros a entrar en aguas españolas (17), y de otro por la orden del Ministerio de Industria y Comercio cursada al director general de Comercio prohibiendo la exportación de toda clase de comestibles el 25 de julio de 1936 (18).

La orden que prohibía exportar productos agrícolas indignó a los agricultores y exportadores levantinos. Ante sus protestas fue rectificada por otra eximiendo de la prohibición a algunas exportaciones agrícolas levantinas (19). La carencia de navios se solucionó mediante la contratación de los servicios de buques extranjeros. Así, por ejemplo, el Comité Ejecutivo Popular de Valencia contrató los servicios de la compañía británica Mc. Andrews, La Roda Herm., Alexander D'Hamilton, etc. Las gestiones de la Delegación de Agricultura, Comercio e Industria del citado Comité consiguieron, a finales de 1936, 2.171 autorizaciones de exportación para cítricos y cebollas esencialmente. Estas exportaciones tropezaron con el problema del clearing, que obligó a la Delegación a negociar acuerdos bilaterales de intercambio de mercancías, independientemente del Ministerio de Industria y Comercio, con Francia, Bélgica, Gran Bretaña y otros países europeos (20).

En el campo se había producido un importante proceso revolucionario que alteró las relaciones de producción. Éste se vió invadido por un movimiento de ocupación de tierras que en muchas ocasiones fueron colectivizadas. Los comités agrícolas de la CNT y de la UGT de algunas localidades levantinas iniciaron ensayos de explotación colectiva de la tierra. Según los datos oficiales del IRA de agosto de 1938 y las recientes cuantificaciones apor-

(16) VIÑAS, A., y otros: Política comercial exterior de España (1931-1975), B. Ex. E. (S.E.E.), Madrid, 1979, t. I, p. 141.

(17) SMYTH, T. M.: La CNT al Pais Valencià, E. Climent, Valencia, 1977, p. 98.

(18) Gaceta de Madrid, Madrid, 26-7-1936, p. 856.

(19) «Orden del Ministerio de Industria y Comercio del 30-7-1936", Gaceta de Madrid, Madrid, 1-8-1936, p. 993.

(20) GIRONA, A.: Guerra i Revolució al País Valencià, tres i cuatre, Valencia, 1986, pp. 61-64. 
tadas por Aurora Bosch (21), en el Levante español se expropiaron 549.478 hectáreas, de las que 169.419 eran explotadas en régimen colectivo por más de 450 colectividades. Dentro de esta coyuntura, los sindicatos obreros pasaron a desempeñar un papel importante en la producción agrícola. Hay que matizar que la expropiación de tierras sólo afectó al 16,74 \% de la superficie total útil del Levante y la colectivización al 5,16\%, lo cual quiere decir que el resto del territorio siguió en manos particulares o municipales.

Pese a su limitación supercial, las experiencias sindicales en la explotación de la tierra y la falta de autoridad del Gobierno de la República en el levante Español durante los primeros meses de la guerra dieron pie a estas organizaciones obreras para que intentasen acceder también al control de la comercialización de lo que cultivaban. Entre septiembre y octubre de 1936, la CNT y la UGT de la región levantina, a través de sus federaciones agrícolas, formaron el Consejo Levantivo Unificado de Exportación Agrícola (CLUEA) con la intención de canalizar a través del mismo la exportación de los cítricos. EI CLUEA nació teóricamente como órgano rector de la exportación naranjera delegado del Ministerio de Industria y Comercio con residencia en Valencia; sin embargo, el Gobierno nunca le concedió tal facultad y durante toda su existencia tuvo que actuar como una empresa de exportación más, aunque con magnánimo poder $y$ amplias facultades.

La organización del CLUEA constaba de cinco secciones: Regulación, Financiera, Transportes, Propaganda y Estadística, y de un Comité Ejecutivo formado por 24 miembros (12 de cada sindical), implicados todos ellos en el negocio naranjero y presididos por un cenetista, Bartolomé Pascual, pese a que el proyecto por el que se creó el CLUEA concedía la dirección del mismo al delegado de Agricultura, Industria y Comercio de Valencia. Este hecho ratifica aún más la circunstancia de que el CLUEA actuase como una empresa privada de exportación y no como un engranaje del mecanismo estatal, como pretendian sus creadores. La organización del CLUEA se completaba con delegaciones en el extranjero, en realidad oficinas comerciales de las que llegaron a funcionar durante la campaña 1936-1937 unas 30 en toda Europa.

EI CLUEA se encargaba de todo el proceso exportador, desde la confección, vigilancia de la calidad, precios y cantidad de fruto a exportar hasta la entrega del producto en los mercados internacionales. El proceso se inicaba en los más de 270 Consejos Locales Unificados de Exportación de Frutos (CLUEFs), que controlaban 1.500 almacenes de confección de naranjas en

(21) $\mathrm{BOSCH}, \mathrm{A}$.: Ugetistas y libertarios. Guerra civil y revolución en el País Valenciano, 19361939, I.A.M.-D.P.V., Valencia, 1983, pp. 236-244. Y «Las colectivizaciones: estado de la cuestión y aspectos regionales", comunicación presentada al Congreso 50 anys (1936-1986) Valencia capital de la República, Valencia, abril de 1986. 
todo el Levante español. Los CLUEFs confeccionaban la naranja y la entregaban al CLUEA para su exportación. En sí se trataba de una organización sindical de todo el proceso de exportación naranjera, una transposición de los postulados colectivistas al terreno de la comercialización citrícola (22).

Paralelamente al CLUEA, y con el fin de socializar y canalizar la exportación del pimentón, el segundo producto en importacia que comercializaba la agricultura levantina, se había constituido en Orihuela el 14 de octubre de 1936 el Control Central de Exportación (CCE). Era una sociedad mercantil nacida sin ningún tipo de escritura pública ante Notario y sin estar inscrita en el Registro Mercantil de la provincia de Alicante. Se constituyó con una simple acta en la que se hizo constar la voluntad de sus componentes en cuanto a su creación y sus fines: exportar pimentón. Empezó sus operaciones con un capital de 100.312,65 pesetas, aportado por cinco de sus componentes, antiguos exportadores individuales, que pronto ascendió a 256.614,42 pesetas. El CEE no revestía la forma ni los requisitos legales necesarios para calificarlo como una de las sociedades para cuya constitución se daban reglas y normas en el Código de Comercio. Se trataba de la socializaclón de un negocio desarrollado anteriormente de forma individual por varias personas y en el que se dio entrada a otras por razón de sus conocimientos o por su relieve social, reconociendo participación en los beneficios a los antiguos propietarios. Sin embargo, pese a no estar regulada su constitución por el Código de Comercio y haber nacido como fruto de una socialización, su sistema de trabajo, su composición y sus fines se ajustaron a los de una sociedad mercantil colectiva que comerció con el pimentón durante 1936-1937 (23).

La exportación de cebolla estuvo regulada en un primer momento por la Deleqación de Agricultura del Comité Ejecutivo Popular de Valencia. Posteriormente pasó a manos de una Comisión Ejecutiva de la Junta provincial de Valencia de Productores-Exportadores de cebolla elegida en la asamblea celebrada por ésta el 27 de agosto de 1936 bajo el amparo del Comité Ejecutivo Popular de Valencia. Definitivamente, cuando el Comité valenciano se desentendió de la exportación directa, se constituyó un Comité de Enlace de

(22) Vid. BOSCH, A.: «Textos II. Naranja y guerra civil: El CLUEA», en Colectivistas (19361939), almudin, Valencia, 1980, pp. 59-118. Y «La col-lectivització de l'exportació de citrics: el Consell Llevantí Unificat d'Exportació Agrícola (CLUEA), 1936-1937", en Estudis d'História Agrària N. ${ }^{\circ}$ 4, Barcelona, 1982, pp. 195-213. GIRONA, A.: «La campaña tarongera de 1936-1937 al País Valencià: anàlisi de l'experiència del CLUEA", comunicación presentada a la /I Assamblea d'Historria de la Ribera, Algemesi, 1981. Y ABAD, V.: «EI CLUEA: ¿Una experiencia frustrada? La campaña naranjera 1936-1937", en Actes del Congrés del Bicentenari de la Taronja 1781. 1981, Carcaixent, 1983, pp. 53-65.

(23) Archivo Histórico de Alicante (AHA): Tribunal Provincial Económico-Administrativo de Alicante, «Expediente del Control Central de Exportación», sección Hacienda, serie HG, sig. 1830. 
Productores-Exportadores de cebolla CNT-UGT que, con una organización semejante a la del CLUEA, dirigió la exportación de la cebolla durante el resto de la campaña 1936-1937 (24).

Ninguna de estas tres entidades exportadoras dominó todo su sector. Las cooperativas de las Federaciones Provinciales Campesinas (FPCs), los propietarios individuales y las Comisiones y Consejerias Provinciales de Abastos también controlaron importantes contingentes de la agricultura de exportación levantina.

La Consejería Provincial de Abastos de Alicante, por ejemplo, envió a Marsella, Orán y Casablanca $253.000 \mathrm{Kg}$. de naranjas, $60.000 \mathrm{Kg}$. de limones y $66.500 \mathrm{Kg}$. de pimentón durante la campaña 1936-1937. Esta Consejería nació en los primeros momentos de la sublevación bajo el denominativo de Junta Provincial de Abastos con la misión de aprovisionar a las columnas que se formaban para combatir. En octubre de 1936 se convirtió en Comisión Provincial de Abastos cumpliendo las disposiciones del Gobierno (25) y ampliando sus actividades con el fin de cubrir tanto las exigencias alimenticias de la población como las de las actividades industriales. Fue entonces cuando organizó las exportaciones de lo que la provincia de Alicante producia para entregarlas en el extranjero a cambio de lo que se precisaba importar. Estableció delegaciones de compra en Marsella y Orán y creó una flotilla minúscula con embarcaciones de pequeño tonelaje (vapor «Ri-Ri», "Pilote Niviere», gabarra "Villerroy», etc.) para efectuar los transportes. En marzo de 1937, cumpliendo una Orden del Ministerio de Comercio (26), pasó a denominarse Consejería Provincial de Abastos y a tener una organización dependiente del Consejo Provincial de Alicante. Sin duda, la labor desarrollada por la Comisión primero y por la consejería después tuvo gran importancia atendiendo a la función social que desempeñó y a la cantidad de mercancías que pasaron por sus manos, de suerte que controló parte de la agricultura de exportación levantina (27).

EI CLUEA, pese a compartir las exportaciones de los cítricos con las Consejerías Provinciales de Abastos, con los propietarios individuales y con las

(24) GIRONA, A.: Guerra i Revolució... o. c., pp. 191-198.

(25) «Decreto del Ministerio de Industria y Comercio del 3-10-1936 disponiendo la constitución de la Comisión Nacional de Abastecimiento", Gaceta de Madrid, Madrid, 4-10-1936, pp. 129130. Y «Orden del mismo Ministerio del 23-10-1936 disponiendo la constitución de Comisiones Provinciales de Abastos, Gaceta de Madrid, Madrid, 24-10-1936, p. 453..

(26) «Orden del Ministerio de Comercio del 8-3-1937 encomendando a los Consejos Provinciales y Municipales las funciones de abastecimientos», Gaceta de la República, Valencia, 10-3-1937, p. 1.137.

(27) CONSEJO PROVINCIAL-ALICANTE. CONSEJERIA PROVINCIAL DE ABASTOS: $M e$ moria 1936-julio-1937, Modernas Gráficas Gutemberg, Alicante, S. A. (1937). 
cooperativas de las FPCs (federaciones nacidas con el apoyo del Partido Comunista y con la finalidad de defender al pequeño propietario del proceso colectivista (28)) y pese a quedar fuera de su radio de acción el sur de la provincia de Alicante y toda Murcia (29), fue la organización exportadora de cítricos más importante del Levante español durante la campaña 1936-1937. Logró exportar 5.300.000 Qm. de cítricos. Observando las importaciones citricolas belgas de la campaña 1936-1937 difundidas por CLUEA («Revista mensual de agricultura y exportaciónm, Valencia, octubre de 1937) (30) se aprecia que el CLUEA entregó el $69 \%$ de los cítricos que se vendieron en el mercado belga; Murcia, el $24 \%$; la FPC * ${ }^{*}$ el $5 \%$, y el Comité de Abastos ${ }^{*}$, el $2 \%$. El predominio del Cluea en las exportaciones citrícolas resulta evidente ante estas cifras.

A nivel estatal, para coordinar la acción ministerial en cuanto a la regulación y financiación del comercio exterior, entre otras funciones, se creó en noviembre de 1936 la Comisaría General de Economía vinculada al titular de la cartera de Hacienda (31). Creada la Comisión General de Economía, el Ministerio de Hacienda procedió a adscribir especialmente a ella los servicios relativos a la producción y comercio de los agrios, canalizando los pagos para la campaña exportadora 1936-1937 a través del Banco Exterior de España. Éste dispuso la concesión de un anticipo equivalente al $50 \%$ del valor medio del fruto a exportar para los exportadores o entidades que realizasen la exportación con el fin de que las operaciones de la misma tropezasen con los mínimos inconvenientes; anticipo que en la práctica no excedió del $33 \%$ del valor de la mercancía a exportar (32).

El 2 de diciembre de 1936 la Presidencia del Consejo de Ministros sometió, mediante decreto (33), la exportación de productos nacionales al extran-

(28) Sobre las Federaciones Provinciales Campesinas, ver para Valencia BOSCH, A.: Ugetistas y libertarios. Guerra y revolución en el País Valenciano 1936-1939, Institución Alfons el Magnànim, Valencia, 1983, pp. 114-115; y para Alicante, GUARDIOLA, A.: Problemas Campesinos. Necesidad de la Federación Provincial Campesina, Alicante, diciembre 1936.

(29) «Informes detallados de los CLUEFs existentes", AHN-GC, Salmanca, Serie Madrid PS, leg. 2.157.

(30) $A B A D, V$, reproduce la información facilitada por la revista CLUEA, en Historia de la Naranja 1781-1939, Comité de Gestión de la Exportación de Frutos Cítricos, Valencia, 1984, p. 343.

(31) «Orden de la Presidencia del Consejo de Ministros del 2-11-1936 creando la Comisaría General de Economía", Gaceta de la República, Valencia, 10-11-1936, p. 674.

(32) «Decreto del Ministerio de Hacienda del 2-11-1936 adscribiendo la producción, exportación y comercialización de agrios a la Comisaría General de Economía», Gaceta de la República, Valencia, 10-11-1936, p. 675. Y «Orden del Ministerio de Hacienda del 20-11-1936 disponiendo se conceda el anticipo de un $33 \%$ del valor de los agrios a exportar como máximon, Ibidem, Valencia, 21-11-1936, p. 739.

(33) Gaceta de la República, Valencia, 3-12-1936, p. 859. 
jero a la previa autorización de la Dirección General de Comercio Exterior dependiente del Ministerio de Comercio, centralizó la negociación de los efectos y la tramitación de los documentos de las expediciones a través del Banco Exterior de España y sujetó a la previa autorización del Ministerio de Comercio las operaciones de compensación de mercancías realizadas por particulares o entidades en el comercio exterior. La repercusión más importante de este Decreto fue la de terminar con la autonomía exportadora del Levante español, esencialmente con la que había desarrollado el Comité Ejecutivo Popular de Valencia, tal y como hemos visto.

Hay que matizar que este decreto no tuvo las mismas consecuencias en toda la República, ya que, por ejemplo, no fue aplicado en la Cataluña autónoma hasta agosto de 1937 (34), en plena euforia centralizadora del Estado. Sin embargo, sí que se puede afirmar que a partir de su promulgación y durante la campaña 1936-1937, la agricultura de exportación levantina estuvo regulada por el Ministerio de Comercio y por el de Hacienda, aunque su control permaneció en manos de particulares y entidades socializadas, sindicalizadas o provincializadas.

\section{ETAPA DE CONTROL CENTRALIZADO (JUNIO 1937-MARZO 1938)}

Tras los sucesos de Barcelona y la crisis final del Gobierno de Largo Caballero, bajo él qưe se había legislado la regulación del comercio exterior, el nùevo Gobierno Negrín prosiguió con la política de fortalecimiento estatal (35). A nivel de comercio exterior ésta se tradujo en el control centralizado directo de las exportaciones de la agricultura levantina, sobre las que ya había actuado con anterioridad la Comisaría General de Economía en el caso de los cítricos, y en una férrea regulación de las exportaciones e importaciones del resto de mercancías ejercida por el Ministerio de Hacienda y Economía (36) que absorbió las funciones del disuelto Ministerio de Comercio (37).

(34) Vid. BRICALL, J. M.: Política económica de la Generalitat. Evolució i formes de la producció industrial, eds. 62, Barcelona, 2. ${ }^{\text {a }}$ ed. 1978, pp. 159-168.

(35) AROSTEGUI, J.: «LOs componentes sociales y políticos», pp. 88-90, en La guerra civil española 50 años después, Labor, Barcelona, 1985, pp. 45-122.

(36) «Decreto del Ministerio de Hacienda y Economía del 13-8-1937 disponiendo queden sometidas a la libre autorización de dicho Ministerio las mercancías a exportar e importar», Gaceta de la República, Valencia, 15-8-1937, pp. 636-637.

(37) Para una esquemática evolución de los ministerios y sus ocupantes durante la guerra vid. GARCÍA-NIETO, M. ${ }^{a}$ C., y PÉREZ, M. ${ }^{a}$ del C.: «Los partidos políticos y la organización del poder en la España republicana: aproximación cuantitativa», en Estudios de Historia de España (Homenaje a Manuel Tuñón de Lara), eds. U.I.M. Pelayo, Madrid, 1981, t. 2, pp. 327-342. 
Por lo que a la agricultura de exportación levantina se refiere, el Ministerio de Hacienda y Economía puso en marcha desde junio de 1937 el Plan de las Centrales de Exportación. Con ellas el Estado pretendia sustituir a la iniciativa privada en la financiación de las exportaciones y someter a un mecanismo de austeridad y fuerte rendimiento al comercio exportador para que éste sirviera a las líneas que inspiraba la política de divisas del Gobierno. El proyecto consistía en fundir, mediante las Centrales de Exportación, a los productores con el Estado, sin perjuicio de utilizar al servicio de esta empresa la aportación técnica de los trabajadores y especialistas de cada rama de la explotación.

La primera en constituirse fue la Central de Exportación de Cebolla (CEC), que experimentalmente, pero con una eficacia real que dio pie para continuar con el proyecto, se encargó de la regulación, financiación, transporte y propaganda de la exportación de cebolla. Su sede se estableció en Valencia con atribuciones en todo el territorio de la nación (38). La consecuencia inmediata de su creación fue el cese de actividades del colectivismo comercial de la cebolla impulsado durante la campaña 1936-1937 por el Comité de Enlace de Productores-Exportadores de Cebolla CNT-UGT.

A la CEC siguieron en agosto del mismo año la Central de Exporación de Pimentón (CEP), con sede en Murcia (39), y la Central de Exportación de Uva de Mesa (CEUM), con sede en Valencia (40), y en septiembre, la Central de Exportación de Agrios (CEA), con sede en Valencia (41). Inmediatamente empezaron a desaparecer las sindicaciones y socializaciones de exportadores. El CCE de Orihuela acordó su disolución el 21 de septiembre de 1937 y el 23 de septiembe del mismo año se practicó el inventrio balance de disolución (42). EI CLUEA fue intervenido por orden del Ministerio de Hacienda y Economía de 6 de octubre de 1937 (43) y declarado en estado de liquida-

(38) «Decreto de 12-6-1937 y orden de 15-6-1937 del Ministerio de Hacienda y Economía creando la Central de Exportación de Cebollas», Gacetas de la República, Valencia, 13-6-1937 у 30-6-1937, pp. 1.197-1.198 y 1.430-1.431.

(39) «Decreto de 6-8-1937 y orden de 10-8-1937 del Ministerio de Hacienda y Economía creando la Central Pimentonera", Gacetas de la República, Valencia, 7-8-1937 y 13-8-1937, pp. 527 y 616-617.

(40) «Decreto de 6-8-1937 y orden de 10-8-1937 del Ministerio de Hacienda y Economía creando la Central de Exportación de Uva de Mesa», Gacetas de la República, Valencia, 7-81937 y 14-8-1937, pp. 528-529 y 627-628.

(41) «Decreto de 6-9-1937 y orden de 11-9-1937 del Ministerio de Hacienda y Economía creando la Central de Exportación de Agrios», Gacetas de la República, Valencia, 8-9-1937 y 13-9-1937, pp. $980-981$ y 1.052-1.055.

(42) AHN: Expediente citado.

(43) Gaceta de la República, Valencia, 12-10-1937, p. 137. 
ción por el mismo Ministerio el 14 de abril de 1938, alegando que al existir las Centrales de Exportación se consideraba innecesaria y perturbadora la coexistencia de organismos con fines idénticos (44).

Tras esta serie de medidas, las Centrales del Gobierno pasaron a controlar la agricultura de exportación levantina durante las campañas 1937-1938 y 1938-1939, desplazando a los particulares y entidades que ejercieron dicho control en la campaña anterior.

Hubo dos modelos de Centrales de Exportación, según las funciones asignadas a cada una por las órdenes correspondientes. Uno el de aquellas centrales que se encargaron exclusivamente de la comercialización de las mercancias. Tal fue el caso de la CEC y de la CEUM. Su misión consistía en regular la exportación; concertar con los productores las condiciones en que éstos tenía que entregar sus productos a la central; concertar créditos en el Banco Exterior de España para la financiación de las exportaciones, con la obligación de realizar todas las operaciones bancarias a través del citado banco; fijar las normas para situar los productos en condiciones de exportación, standarización de los mismos, envases, confección de marcas y circunstancias en que se tenían que realizar las inspecciones de sanidad y calidad, de acuerdo con los servicios oficiales encargados a las mismas; concertar los contratos de transporte, seguros y almacenajes; concertar los contratos de venta en los mercados exteriores y organizar las agencias de ventas necesarias en el extranjero, y encargarse de la propaganda genérica de las mercancias.

El otro modelo fue el de aquéllas que no sólo se ocuparon de la comercialización, sino también de aspectos concretos de la producción. En este sentido, la CEP, además de las operaciones comerciales, tenía las funciones de producción siguientes: Proponer al Ministerio de Hacienda y Economía las normas que debían regular la producción e industrialización del pimentón. Vigilar la fabricación y el cumplimiento de las normas para evitar adulteraciones. Fijar las bases de los contratos entre agricultores e industriales para la entrega de las materias primas. Fijar las características de los tipos de pimentón que tenía que producirse, previo informe de la Estación Oficial Pimentonera. Centralizar la adquisición y distribución de materias primas. Realizar estadísticas de producción y existencias en fábricas y almacenes. Y propuestas al Ministerio de Trabajo y Asistencia Social para resolver problemas de la producción pimentonera y a la Dirección General de Industria para sancionar las infracciones de las normas sobre calidades y regulación de la industria. Por lo que se refiere a la CEA, a ésta además de encargarle las operaciones co-

(44) Ibidem, Barcelona, 17-4-1938, pp. 348-349. 
merciales correspondientes, se le asignó el suministro a las fábricas de derivados de los productos necesarios para la industria y la fijación de los precios de cesión de los mismos, así como los precios de los derivados obtenidos; la determinación de los fraudes en la fabricación y venta de los subproductos citrícolas y su persecución, y el estudio de los distintos aprovechamientos del fruto para aplicaciones industriales y trabajos de investigación para la mejora en los procedimientos de fabricación y obtención de nuevos productos.

\section{CUADRO 4}

\section{Composición de los Consejos de Administración de las entidades exportadoras estatales de la agricultura levantina}

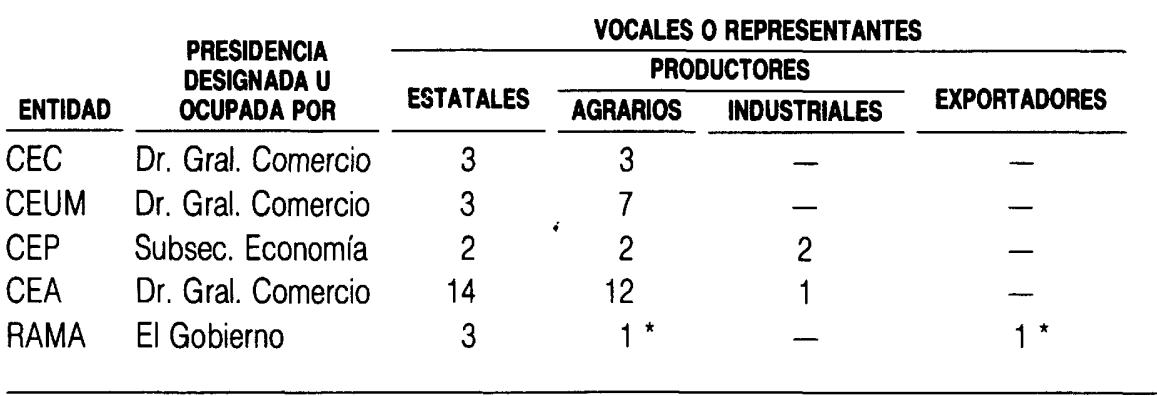

* Uno por cada zona naranjera. En 1938-1939, sólo Castellón.

Con la llegada al Mediterráneo de las tropas franquistas y la toma de Castellón y Burriana entre junio y julio de 1938, la agricultura de exportación castellonense pasó a manos de las tropas ocupantes. El nuevo régimen allí instalado creó el 14 de noviembre de ese mismo año la Rama de la Naranja Dul$c e$, con el cometido de organizar desde Castellón la exportación naranjera de las zonas conquistadas. La Rama tuvo un funcionamiento y una estructura similar a la de la CEA; pero pese a organizar el comercio naranjero basándose en postulados semejantes: control estatal, base cooperativa y centralización de ventas, la Rama se diferenció de la CEA y del resto de Centrales de Exportación republicanas en varios aspectos, de entre los que quiero destacar uno por su significación: la Rama de la Naranja Dulce dio cabida en su consejo de administración a los representantes de los exportadores, mientras que las Centrales de Exportación, no; porque éstas últimas pretendian fundir a los productores con el Estado y eliminar la iniciativa privada o sindical en la financiación de las exportaciones. A la Rama sólo le preocupaba la expor- 
tación y recuperar el orden anterior al proceso revolucionario iniciado durante la República (ver cuadro 4). Lo cierto es que durante la campaña 19381939 los dos Gobiernos en litigio participaron de la agricultura de exportación levantina, sumamente codiciada. La economía citrícola quedó en manos de dos organizaciones que, como afirma Vicente Abad (45), desde presupuestos ideológicos irreconciliables persiguieron un mismo objetivo: «poner en manos de sus respectivas autoridades económicas el mayor número posible de divisas a través de la venta de la naranja en el extranjero» (46).

(45) ABAD, V.: Historia de la Naranja..., o. c., p. 365.

(46) Para la CEA y la Rama de la Naranja Dulce, vid., ABAD, V.: Historia de la Naranja..., o. c., pp. 350-375, y GARCÍA, C.: Estudio sobre la exportación y venta de la naranja española en el Reino Unido, Valencia, 1940. 